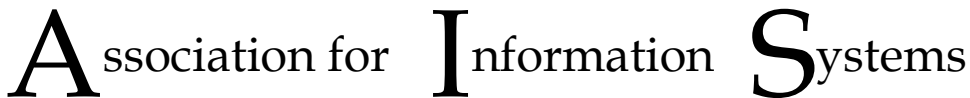

Research Paper

ISSN: 1536-9323

\section{Business Intelligence Capability: The Effect of Top Management and the Mediating Roles of User Participation and Analytical Decision Making Orientation}

\author{
Uday R. Kulkarni \\ Arizona State University, USA \\ uday.kulkarni@asu.edu \\ José Antonio Robles-Flores \\ Universidad ESAN, Peru \\ Aleš Popovič \\ University of Ljubljana, Slovenia \\ NOVA IMS, Universidade Nova de Lisboa, Portugal
}

Abstract:

In this study, we draw on the structurational model of technology in an institutional setting to investigate how top management affects the development of a firm's business intelligence (BI) capability. We propose a multiple mediator model in which organizational factors, such as user participation and analytical decision making orientation, act as mediating mechanisms that transmit the positive effects of top management championship to advance a firm's BI capability. BI capability has two distinct aspects: information capability and $\mathrm{BI}$ system capability. Drawing on data collected from 486 firms from six different countries, we found support for the mediating effects of top management championship through user participation and analytical decision making orientation. These findings contribute to a nuanced understanding of how firms can develop BI capability. This study is one of the first to comprehensively investigate the antecedents of BI capability.

Keywords: Business Intelligence, Business Intelligence Systems, Top Management Championship, User Participation, Analytical Decision Making Orientation, Information Capability, Business Intelligence System Capability.

Fiona Fui-Hoon Nah was the accepting senior editor. This paper was submitted on November 22, 2015, and went through 2 revisions. 


\section{Introduction}

The information technology (IT) business value literature has highlighted the potential of information systems to improve decision making in order to advance firm performance (Davern \& Kauffman, 2000; Melville, Kraemer, \& Gurbaxani, 2004; Mithas, Ramasubbu, \& Sambamurthy, 2011). Studies on firm performance have found information systems to support timely decisions, promote innovation, and offer a means to manage uncertainty central to the business environment (Dewett \& Jones, 2001; Melville et al., 2004). High-quality information (i.e., relevant, reliable, accurate, and timely information) (Popovič, Hackney, Coelho, \& Jaklič, 2012; Wixom \& Todd, 2005) enables enhanced decisions and can, in turn, stimulate improvements in firm performance (Raghunathan, 1999). To leverage the benefits of high-quality information, firms are increasingly investing in information systems (Habjan, Andriopoulos, \& Gotsi, 2014).

During the last decade, firms have invested significant resources in business intelligence (BI) systems to achieve competitive advantages ( $\mathrm{Li}$, Hsieh, \& Rai, 2013). BI systems are complex technological solutions that provide quality information from well-designed data stores connected to business-friendly tools that allow their users to timely access, effectively analyze, and insightfully presenta information, which enables them to make better decisions and take the right actions (Elbashir, Collier, \& Davern, 2008; Li et al., 2013). BI systems provide business value via direct (i.e., time savings in decision making processes) (Watson, Goodhue, \& Wixom, 2002) and indirect means (i.e., improvements in performance and comparative advantage) (Popovič, Hackney, Coelho, \& Jaklič, 2014). Gartner has consistently rated BI systems among the top 10 strategic technologies (Gartner, 2016a) and the most important key issues for CIOs (Gartner, 2016b; Luftman \& Ben-Zvi, 2010). Despite ongoing investments in BI and their growing importance, not all firms are equally successful in developing BI capabilities (Audzeyeva \& Hudson, 2016). Hence, in this paper, we focus on understanding the factors that influence how organizations build $\mathrm{BI}$ capability and the mechanism through which they do so.

A topic regularly researched in the context of enterprise systems is the role of a firm's top management in introducing and adapting advanced technologies that impact organizational capabilities (Dong, Neufeld, \& Higgins, 2009; Ragu-Nathan, Apigian, Ragu-Nathan, \& Tu, 2004). Specifically, in addition to offering a vision and guidelines, top management is responsible for providing the active support that firms need for managing the change in business processes that the new technologies impact, facilitating lower user resistance, and explicitly exhibiting commitment through communication and actions to ensure success. Because of these challenges, research on understanding the role of top management in developing organizational capabilities from enterprise systems has continued to garner interest. As specialized technologies emerge to serve organizations' evolving needs, we will need to identify and study the factors that influence how organizations build the capabilities associated with such technologies. Researchers have observed that top management's commitment to a specific complex technology in terms of organizational goals and expectations has resulted in their firms' successfully implementing and subsequently assimilating that technology (Chatterjee, Grewal, \& Sambamurthy, 2002; Dong et al., 2009; Purvis, Sambamurthy, \& Zmud, 2001). However, research has not studied this phenomenon in the BI context, which we address here.

$\mathrm{BI}$ systems have several characteristics that distinguish them from other enterprise-level technologies (Popovič et al., 2012) and affect the BI capability-building phenomenon. First, BI mainly involves the managerial user; hence, it may require different efforts to generate a buy-in for its use. Second, its use is generally voluntary (Grublješič \& Jaklič, 2015; Wixom \& Quaadgras, 2013); thus, users may want to actually see the benefits of using it, which creates a need for different incentives for its use. Third, organizations primarily implement it for strategic reasons; BI systems focus less on reducing costs or increasing operational efficiency and more on increasing managerial effectiveness and for building competitive advantages. Hence, the mechanisms through which top management affects a firm's BI capability differ from those for building capabilities with other enterprise systems, such as ERP. Top management's actions to transform the prevailing institutional structures and reinforce norms that value the use of information in decision making will likely result in higher levels of organizational capabilities in this domain (Sharma \& Yetton, 2003). As such, we need to examine top management's influence on BI capability's development to understand the exact nature of the phenomenon that governs the complex interactions between multiple related organizational factors. Thus, the following question frames our investigation:

RQ: Through what specific mechanisms does top management influence how organizations build BI capability? 
Drawing on relevant literature, we identify two organizational factors (i.e., user participation in the ongoing evolution of $\mathrm{BI}$ and analytical decision making orientation) as mediating variables that transmit the effect of top management championship on building $\mathrm{BI}$ capability. We model $\mathrm{BI}$ capability itself as comprising two components: information capability and BI system capability. Adopting the firm as the unit of analysis, we propose and empirically test our research model using data from 486 medium- and large-sized firms from six different countries that have implemented BI systems. We make two primary contributions to the IT capability and $\mathrm{BI}$ literature. First, to the best of our knowledge, this study is the first to comprehensively investigate the antecedents of $\mathrm{BI}$ capability on a large scale and to specifically link top management championship to a firm's BI capability. Second, our results highlight that this link is not entirely direct; other organizational factors, as our research model hypothesizes, mediate this relationship.

\section{Theoretical Development}

We ground our research model in the structurational model of technology (Orlikowski, 1992), which employs the tenets of structuration theory (Giddens, 1979, 1984) to reconstruct the relationship between organizations and technology. We posit that top management championship, along with other organizational factors, has a major influence on the adoption and ongoing enhancement of $\mathrm{BI}$ capability. Starting with a brief overview of the literature on IT capability and its variations, we discuss how we conceptualize BI capability. We use the structurational model of technology as our theoretical foundation to explain the institutional structures through which organizations build BI capability. We then describe our mediating constructs and the hypothesized relationships with the help of these theoretical foundations. Figure 1 presents our conceptual research model.

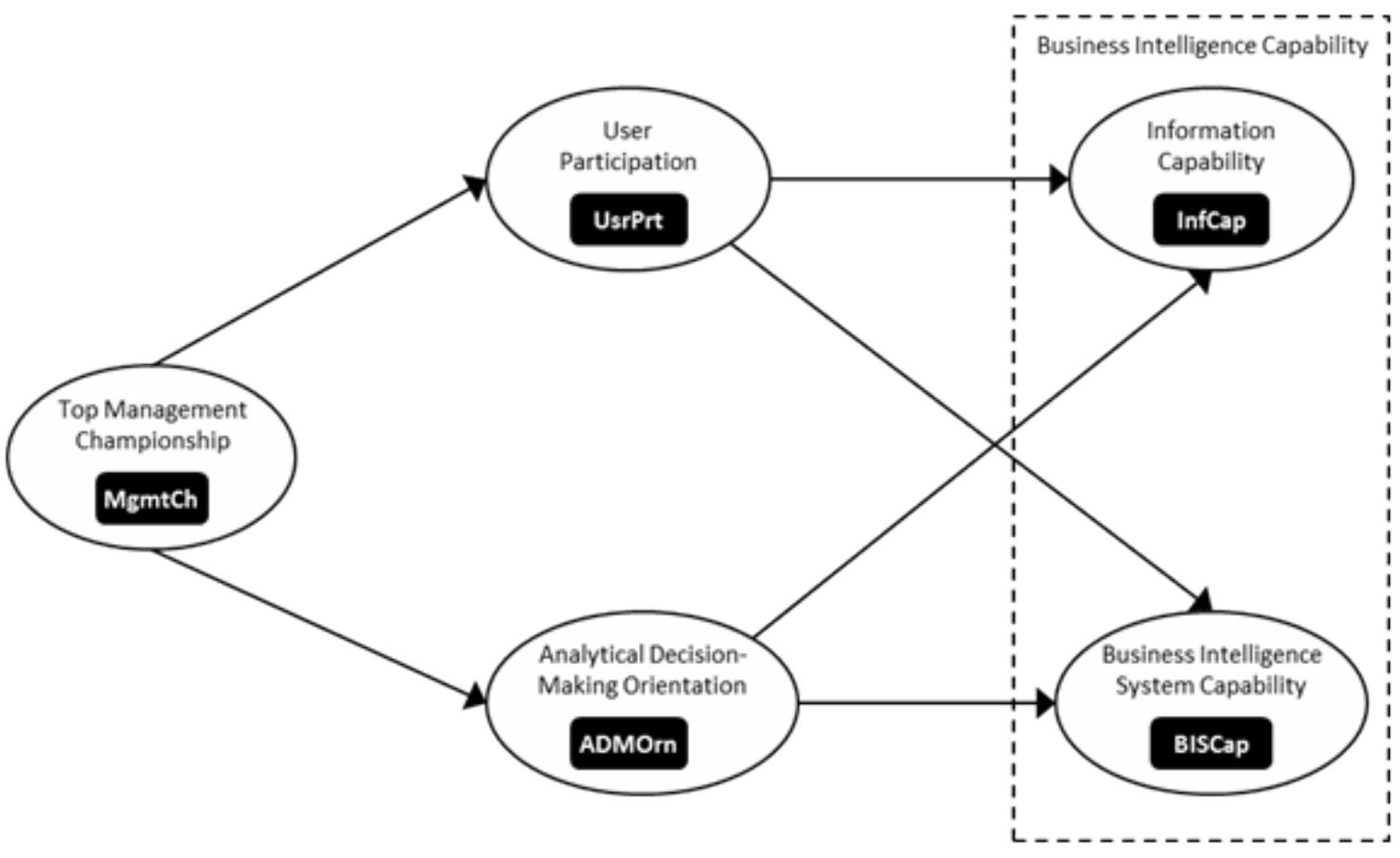

Figure 1. Conceptual Research Model

\subsection{Business Intelligence Capability}

The BI capability concept originates from IT capability, which researches have widely studied in the information systems (IS) literature (Bharadwaj, 2000; Kim, Shin, Kim, \& Lee, 2011; Sabherwal \& Jeyaraj, 2015). IT capability is an organizational capability that represents the "ability to mobilize and deploy ITbased resources in combination or copresent with other resources and capabilities" (Bharadwaj, 2000). IS scholars have argued that variations in IT capabilities are sources of differences in performances across firms; therefore, IT capability research has primarily focused on how IT capabilities affect firm performance 
(Chae, Koh, \& Prybutok, 2014; Kim, Shin, Kim, \& lee, 2011; Wang, Liang, Zhong, Xue, \& Xiao, 2012). However, few studies, such as Bhatt and Grover (2005), have focused on the factors that influence how organizations build IT capabilities.

A review of the literature reveals that IT capability is an omnibus concept because IT permeates every process and function of an organization. Therefore, researchers have generally conceptualized IT capability as a higher-order construct to include various combinations of resources such as IT infrastructure, IT personnel, IT management, and other similar concepts. Table 1 (Part I) shows the conceptual diversity with which researchers have defined IT capability in key papers published in top business journals since the year 2000. As one can see, although most studies include IT infrastructure as a central component, researchers also see additional complementary factors as contributing to overall IT capability. For example, apart from IT infrastructure, Bharadwaj (2000) and Santhanam and Hartono (2003) include human resources-which comprises technical and IT management skills and other intangibles such as knowledge assets, customer orientation, and so on-in their definition of IT capability. Bhatt and Grover (2005) define IT capability as having three dimensions: quality of IT infrastructure, the business-related knowledge of the IT group, and the quality of the relationship between IT and management groups. Pavlou and El Sawy (2006) define IT capability in terms of the ability to acquire IT infrastructure resources, deploy them through IT-business relationships, and leverage them via technical and managerial skills. Sabherwal and Jeyaraj (2015) describe IT capability in terms of IT architecture, delivery of IT services, and IT management.

Further, IT encompasses myriad technologies, and each of these technologies serves a different purpose and directly impacts performances in different areas of business. Organizations adopt different technologies and build capabilities around them for many reasons such as competitive standing, historical strengths, and so on. Hence, some researchers have conceptualized and studied capabilities associated with specialized types of IT according to the purpose they serve (see Table 1). For example, knowledge-management capability includes the ability to perform specialized processes to acquire, convert, apply, and protect knowledge (Gold et al., 2001). ERP capability refers to the extent of an ERP system's range (the variety of functions supported), reach (the extent of organizational coverage), and geographic scope (Karimi et al., 2007). E-commerce capability refers to a firm's ability to interact with its customers and business partners while conducting business over the Internet (Zhu, 2004; Zhu \& Kraemer, 2002). Researchers have studied these capabilities separately because building each type of specialized IT capability requires different types of resources, faces different types of implementation challenges, has different types of usage and users, and follows different evolution paths. For example, building knowledge-management capability may need a knowledge-sharing culture in addition to technology infrastructure, while e-commerce capability may demand more attention to alignment with external partners and a customer orientation. Thus, the factors that influence how organizations build these specialized capabilities differ.

Our study focuses on BI capability-a special type of IT capability that relates to a firm's ability to provide high-quality information and systems to help decision makers make more effective decisions to better plan for actions and, ultimately, attain better competitive positions. BI capability specifically concerns information delivery and its analysis for managerial use. In contrast to operational systems such as ERP and e-commerce systems that focus on fast and efficient transaction processing, BI systems support analytical decision making, and, thus, organizations use them for knowledge-intensive activities that are inherently less structured. In the $\mathrm{BI}$ environment, one constantly faces challenges in identifying and fulfilling the information requirements of such less structured knowledge-intensive activities and their analytical processing needs (Popovič et al., 2012). Thus, researchers would find it insightful to consider two distinct aspects associated with the development of a BI capability: 1) information capability (i.e., the ability to provide quality information with appropriate levels of detail, relevance, reliability, and timeliness) and 2) BI system capability (i.e., the ability to exploit the information via exploration, manipulation, and customized applications to suit its users' needs) (Işık, Jones, \& Sidorova, 2013). 
Table 1. Review of the Literature on IT Capability and Related Capability Constructs

\begin{tabular}{|c|c|}
\hline Paper & 1) Concept/definition of IT capability \\
\hline Bharadwaj (2000) & $\begin{array}{l}\text { IT capability encompasses IT infrastructure, human IT resources (e.g., technical and } \\
\text { managerial IT skills), and IT-enabled intangibles (e.g., knowledge assets, customer } \\
\text { orientation, and synergy) }\end{array}$ \\
\hline $\begin{array}{c}\text { Santhanam \& Hartono } \\
(2003)\end{array}$ & Same as Bharadwaj (2000) \\
\hline Bhatt \& Grover (2005) & $\begin{array}{l}\text { IT capability has three dimensions: 1) quality of IT infrastructure, 2) IT group's business } \\
\text { experience, and 3) IT-business relationship }\end{array}$ \\
\hline Piccoli \& Ives (2005) & $\begin{array}{l}\text { IT capability encompasses: 1) technical skills, 2) IT management skills, and 3) relationship } \\
\text { between the IS function and the business }\end{array}$ \\
\hline $\begin{array}{l}\text { Ravichandran, } \\
\text { Lertwongsatien, \& } \\
\text { Lertwongsatien (2005) }\end{array}$ & $\begin{array}{l}\text { Authors define IS capability from an IS functional perspective and as having four } \\
\text { components: IS planning sophistication, systems development capacity, IS support maturity, } \\
\text { and IS operations capability }\end{array}$ \\
\hline $\begin{array}{l}\text { Sanders \& Premus } \\
(2005)\end{array}$ & $\begin{array}{l}\text { IT capability is a technological capability used to acquire, process, and transmit information } \\
\text { for more effective decision making }\end{array}$ \\
\hline $\begin{array}{l}\text { Pavlou \& El Sawy } \\
\quad(2006)\end{array}$ & $\begin{array}{l}\text { IT capability has three key dimensions: 1) the acquisition of IT resources, such as } \\
\text { technology assets, IT objects, and the overall IT infrastructure; 2) deployment of IT } \\
\text { resources through tight IT-business relationships, such as IT-business partnering, IT } \\
\text { partnerships, and business-IT vision; and 3) leveraging of IT resources, such as technical IT } \\
\text { skills and human IT resources }\end{array}$ \\
\hline Aral \& Weill (2007) & $\begin{array}{l}\text { IT capability comprises interlocking systems of IT competencies (IT skills, IT management } \\
\text { quality) and practices (IT use intensity for communication, digital transaction intensity, } \\
\text { Internet architecture) }\end{array}$ \\
\hline $\begin{array}{l}\text { Lu \& Ramamurthy } \\
\qquad(2011)\end{array}$ & $\begin{array}{l}\text { IT capability is reflected via IT infrastructure capability (the technological foundation), IT } \\
\text { business spanning capability (business-IT strategic thinking and partnership), and IT } \\
\text { proactive stance (opportunity orientation) }\end{array}$ \\
\hline Kim et al. (2011) & $\begin{array}{l}\text { IT capability comprises IT infrastructure flexibility, IT management capability, IT personnel } \\
\text { expertise, which are related to each other }\end{array}$ \\
\hline Wang et al. (2012) & $\begin{array}{l}\text { IT-related capability is the firm-wide ability to acquire and manage IT resources and to } \\
\text { execute IS management and operational processes. It also includes the ability of the } \\
\text { business function to use IT functionalities, and IT's ability to affect business processes and } \\
\text { to satisfy business requirements }\end{array}$ \\
\hline $\begin{array}{l}\text { Mishra, Modi, \& } \\
\text { Animesh (2013) }\end{array}$ & $\begin{array}{l}\text { IT capability is the ability to leverage IT infrastructure through a combination of IT human } \\
\text { capital and IT-related intangibles }\end{array}$ \\
\hline Chae et al. (2014) & Same as Bharadwaj (2000) \\
\hline $\begin{array}{l}\text { Sabherwal \& Jeyaraj } \\
\text { (2015) }\end{array}$ & $\begin{array}{l}\text { IT capability refers to aspects such as the design of IT architecture, delivery of IT services, } \\
\text { and IT management }\end{array}$ \\
\hline Paper & 2) Concept/definition of specialized types of IT capability \\
\hline $\begin{array}{l}\text { Gold, Malhotra, } \\
\text { \&Segars (2001) }\end{array}$ & $\begin{array}{l}\text { Knowledge management capability comprises knowledge infrastructure capabilities } \\
\text { (comprising technology, structure, and culture) and knowledge process capabilities } \\
\text { (comprising acquisition, conversion, application, and protection processes) }\end{array}$ \\
\hline $\begin{array}{l}\text { Barua, Konana, } \\
\text { Whinston, \& Yin } \\
\quad(2004)\end{array}$ & $\begin{array}{l}\text { Online informational capability }(\mathrm{OIC}) \text { is a firm's ability to exchange strategic and tactical } \\
\text { information with customers and suppliers on-demand }\end{array}$ \\
\hline $\begin{array}{l}\text { Zhu \& Kraemer (2002), } \\
\text { Zhu (2004) }\end{array}$ & $\begin{array}{l}\text { E-commerce capability represents a firm's ability to interact with its customers and business } \\
\text { partners and conduct businesses over the Internet }\end{array}$ \\
\hline $\begin{array}{l}\text { Karimi, Somers, \& } \\
\text { Bhattacherjee (2007) }\end{array}$ & $\begin{array}{l}\text { Authors define ERP capability in terms of: 1) ERP range (functional scope of business } \\
\text { processes that are shared by ERP implementation), 2) ERP reach (organizational scope of } \\
\text { ERP systems linking departments, divisions, the entire company, multiple companies, and } \\
\text { so on), and 3) ERP geography (geographic scope of the ERP implementation, such as } \\
\text { regional, national, and global) }\end{array}$ \\
\hline Mithas et al. (2011) & $\begin{array}{l}\text { Information management capability is the ability to: 1) provide data and information to users } \\
\text { with the appropriate levels of accuracy, timeliness, reliability, security, and confidentiality; 2) } \\
\text { provide universal connectivity and access with adequate reach and range; and 3) tailor the } \\
\text { infrastructure to emerging business needs and directions }\end{array}$ \\
\hline
\end{tabular}


Separating information and $\mathrm{BI}$ system capabilities in this manner agrees with similar conceptualizations in prior literature. For example, one major component of Mithas et al.'s (2011) information management capability is the data-related capability, which the authors describe as the ability to "ensure data and information integrity, reliability, accuracy, timeliness, security, and confidentiality" (p. 246); the other components include system capabilities such as the ability to make the "needed data and information available". Eppler (2006) develop a framework for information quality management that is analogous to our $\mathrm{BI}$ capability. He distinguishes between information and systems capabilities as content and media quality. Eppler's content quality relates to the actual information itself and includes factors such as comprehensiveness, accuracy, clarity, applicability, conciseness, consistency, correctness, and currency. His media quality relates to the management of that information, which includes processes and infrastructure that make information accessible, secure, and maintainable and the usage of information convenient, timely, and interactive. Susarla, Barua, and Whinston (2010) refer to "quality of data" and "quality of the analytical tool" and, thus, distinguish between the information itself and the tools to analyze it. Işık et al. (2013) use the concepts of "data quality", "integration of the Bl", "user access", "flexibility of the Bl", and "risk management support" to refer to these capabilities. The first concept, data quality, relates to the consistency and comprehensiveness of the data and, thus, stresses the importance of good data for BI projects. The other four concepts reflect BI systems' characteristics. Popovič et al. (2014) differentiate "information quality" and "business intelligence systems quality" to separate the information from the information systems by noting that the first one produces the latter.

\subsection{The Structurational Model of Technology and BI Capability}

Institutional theories explain how firms act as institutions in shaping the behavior of agents in them. They are an appropriate foundation for explaining the development of advanced technology capabilities, such as $\mathrm{BI}$, for two reasons. First, because these technology adoptions occur at the organizational level, they reflect firm-wide phenomena in integrating IT into business processes. Second, such innovations require changes in institutional structures and the mobilization of human agents across the organization. Our theoretical foundation lies in the structurational model of technology (Orlikowski, 1992, p. 405), which employs the institutional structures of signification, legitimation, and domination from structuration theory (Giddens, 1979, 1984). The structurational model of technology describes the dualism in the interaction between organizations' structural features and human agents with respect to technology. Our research model draws on this theory to explain how organizations build BI capability.

Orlikowski's (1992) structurational model of technology considers technology as "one kind of structural property of organizations developing and/or using technology" (p. 405). Orlikowski uses structuration theory to reconceptualize the notion of technology and to reformulate the relationship between technology and organizations. She argues that individuals use the signification, legitimation, and domination structures to perform technology-structuring activities-processes through which users interact with technologies to accomplish work. The structurational model of technology theorizes that these interactions involve a dualism: as users use the technology, they recreate and, at times, affect the (technology's) structure itself (Orlikowski, Yates, Okamura, \& Fujimoto, 1995, p. 425). Thus, individuals' technology-structuring activities impact organizations' technological capability. In the context of BI technology, given the inherent interactive nature of technology usage, we contend that this dualism plays a significant role in capability building. The following scenario illustrates the dualism in the user-technology interaction in the context of $\mathrm{BI}$ technologies and shows how a technology-structuring activity can impact an organization's technological capability.

A managerial user such as an airline operations manager at an airport may need to decide which one of the four candidate passengers to assign the only seat available on a connecting flight - the others have to be stranded overnight. An interactive BI tool such as a dashboard may provide the manager with information that is useful for making this decision, e.g., an analysis of each passenger's value (elite status, ticketing class - deep discount vs. full fare), their recent travel experiences (missed connections, upgrades, lost baggage), etc. The interactions with technology (comparing passenger values, drilling down into each passenger's travel history, etc.) are the technology structuring activities the manager performs while making the decision. After making this type of decision many times, the manager may start considering additional information such as: does the passenger have co-travelers (spouses, children, friends), or how essential is it for a given passenger to be connected (one passenger may have a critical event to attend while another may prefer a layover in the city where they are stranded), etc. These new considerations, if made part of the routine decision making process, can be given systematic technology support and the BI tool itself can be improved, a result of the dualism in 
the interaction. $\mathrm{BI}$ capability is thus a product of human-technology process improvement which is triggered by the technology structuring actions of the individual.

In theorizing the structurational model of technology, Orlikowski (1992) interprets the dualism in the interaction between the technology and the individual via the three institutional structures in the context of technology:

Structures of signification represent the organizational rules that inform and define interaction whereby human agents constitute and communicate the meaning and understanding of interpretive schemes. These structures serve as cognitive guides for individuals to understand how they should behave/act with respect to technology. Individuals interact within these structures to reaffirm and challenge them and, thereby, shape them.

Structures of legitimation structures represent a moral order that an organization articulates by validating specific behaviors as being appropriate. These structures serve as normative sanctions that reassure individuals of their behavior/action with respect to technology. Individuals interact with these structures by accepting them as cultural norms and, thereby, sustain them.

Structures of domination structures represent the existence of the asymmetry of authoritative (relating to human) and allocative (relating to material) resources in organizations. These structures serve to induce power (understood as transformative capacity) in individuals to act and accomplish outcomes with respect to technology. Individuals interact within these structures by drawing on the asymmetry and, thereby, confirm them, although individuals may always act to change a particular structure of domination.

Further, Orlikowski et al. (1995) observe that top management can control an organization's prevailing institutional structures to influence users' technology-structuring activities. This broader process, which does not involve activities of technology use but involves the shaping (by top management) of employees' technology use activities, is called metastructuring. For example, metastructuring actions by top management may include their actively sponsoring a particular technology initiative or using rewards and sanctions.

With these abstract concepts from the structurational model of technology, we can define the more concrete and measurable constructs in our conceptual model and explain their hypothesized relationships. We propose that BI capability building occurs due to individual structuring activities that top management's metastructuring actions trigger. The institutional structures of signification, legitimation, and domination explain the connection between the metastructuring actions and the individual structuring activities of technology use, which, in turn affect a firm's BI capability.

\subsection{Top Management Championship for BI}

We use the term top management championship for BI to indicate the extent to which a firm's senior management considers building $\mathrm{BI}$ capability to be strategically important. Extant IS literature has long emphasized the role of top management in firms' integrating complex IT into their core business processes (Dong et al., 2009). Top management championship in this context refers to managerial beliefs about technological initiatives, participation in those initiatives, and the extent to which top management advocates technological advancement (Chatterjee et al., 2002; Purvis et al., 2001).

To portray the top management's role, the IS literature offers several related concepts. Among others, the most frequently used (besides top management championship) concepts include top management support (Thong, Yap, \& Raman, 1996), top management involvement, and top management participation (Jarvenpaa \& Ives, 1991; Liang, Saraf, Hu, \& Xue, 2007). Of these, researchers have used top management support as an umbrella term for describing several different notions, including involvement and participation. (For a comprehensive review, see Dong et al. (2009)). In the majority of studies, including $\mathrm{BI}$ studies, this term has been used to assess its influence on the success of implementation of an information system (or an IS- related project) (e.g., Sharma \& Yetton, 2003; Thong et al., 1996). By contrast, top management's role in our study lies in influencing how organizations build organizational capability, a higher-level goal similar to adopting and assimilating innovative technologies (Chatterjee et al., 2002; Liang et al., 2007; Purvis et al., 2001). Further, consistent with observations from Jarvenpaa and Ives (1991), researchers have mainly embraced an attitudinal and/or a behavioral interpretation of top management-related concepts. Attitudinal interpretations present these concepts as a set of positive attitudes that top management expresses, for example, through involvement or commitment (Keil, 1995; Lewis, Agarwal, \& Sambamurthy, 2003). Behavioral interpretations, on the other hand, advocate an active participant view in which top management directly influences the mutual adaptation between technology and the organization (Guimaraes \& Igbaria, 1997; Jarvenpaa \& Ives, 1991; Markus \& Mao, 2004). We contend that, for organic enhancements such as building $\mathrm{BI}$ capabilities at the organizational level, one 
needs to consider both attitudinal and behavioral interventions. Top management championship represents a combination of beliefs and actions, and research has shown that it impact organizationallevel outcomes in technology assimilation (Chatterjee et al., 2002). Hence, drawing on this extant literature, we chose top management championship for $\mathrm{BI}$ as the main antecedent in our research model.

In terms of the structurational model of technology (Orlikowski, 1992), both the expression of attitude (commitment, beliefs, etc.) and supportive behaviors (resource allocation, sponsorship, etc.) represent top management's metastructuring actions. In general, top management championship is a set of metastructuring actions because it builds the institutional context, conveys norms, and directs attention about how employees may engage in structuring activities related to BI technology. Specifically, via the metastructuring action of articulating the importance of an enterprise-wide role for BI systems, top management introduces a structure of signification in which individuals start understanding how they should behave/act with respect to the new BI systems. By issuing policy communications and providing guidelines with respect to $\mathrm{Bl}$-another metastructuring action-top management invokes a structure of domination in which the rules of participating in business processes that the new BI systems support govern individuals' interaction. By sponsoring new BI initiatives and investing in analytically skilled talent, top management creates new domination structures (via authoritative and allocative resource asymmetry) and, thus, direct (and empower) individuals to accomplish outcomes with the help of the new BI systems. These same metastructuring actions (i.e., sponsoring new BI initiatives and investing in analytically skilled talent) invoke legitimation structures: that is, they reassure individuals of their behavior with respect to expending time and energy in exploring creative ways in which they can embed $\mathrm{BI}$ technology into business processes and decision making tasks. Further, these metastructuring actions allow adjustments to happen on both sides: they alter the practice of the individuals in the organization with respect to technology and they also let the technology adapt to its environments.

Past research has used these metastructuring/structuring phenomena to explain the role of top management in firms' adopting and assimilating advanced technologies for building specialized IT capabilities. Purvis et al. (2001) study the metastructuring actions of top management as the main construct impacting the assimilation of knowledge platforms in organizations. Theorizing from the structurational model of technology, they note that, "the successful use of a new technology often requires the mutual adaptation of the technology and the organizational context into which the technology is being introduced" (p. 121). Chatterjee et al. (2002) explore the influence of three metastructuring actions of top management (i.e., championship, articulation of strategic investment rationale, and coordination between distributed leadership) on Web technology assimilation. Hence, overall, we expect top management's metastructuring actions to positively affect how a firm develops its $\mathrm{BI}$ capability. This general line of argument serves as our starting point for theorizing more specifically about the factors that mediate the relationship between top management championship and BI capability.

\subsection{Mediating Variables}

We theorize that top management's metastructuring actions use two possible pathways with related but distinct constructs-user participation and analytical decision making orientation-which act as mediating variables for an organization to build BI capability. User participation represents a measure of the actions of users: the extent of their involvement in the initial phases and in the continued evolution of $\mathrm{BI}$ systems. Analytical decision making orientation measures the state of the organization: the extent to which an organization encourages decision makers to collect and analyze data relevant to their decisions. In Sections 2.4.1 to 2.4.4, we describe the rationale for conceptualizing these variables, including their theoretical bases and prior usage. We then build our research model with arguments derived primarily from the theoretical basis provided by the structurational model of technology.

\subsubsection{User Participation}

Traditionally, user participation refers to the assignments and tasks that users or their representatives perform during IS development (Barki \& Hartwick, 1994; Hartwick \& Barki, 1994) ${ }^{1}$. Typically, these assignment and

\footnotetext{
${ }^{1}$ Barki and Hartwick (1994) distinguish between user participation and user involvement; the latter is a psychological construct that represents the importance and personal relevance that users attach to a system. Nonetheless, researchers have used participation as a proxy for measuring involvement because participation is an observable behavioral construct. These terms have been used interchangeably inIS success research (Sabherwal, Jeyaraj, \& Chowa, 2006) and we also use them synonymouslyhere.
} 
tasks are the various design-related activities and behaviors that target users or their representatives perform during the initial phases of developing systems. These studies show that user participation results in systems that better fulfill users' requirements, that users more easily accept, and that lead to improved outcomes and more satisfied users (He \& King, 2008; McKeen, Guimaraes, \& Wetherbe, 1994).

Unlike traditional enterprise systems (such as ERP, e-commerce) that mainly automate business processes, the intention behind $\mathrm{BI}$ systems is to primarily assist managers in their decision making tasks. Whether licensed from vendors and customized with the help of experts (from inside or outside the organization) or built in-house for specialized decision-support applications, the requirements of the decision-support applications a BI system is designed to support are initially not completely clear (Wixom \& Watson, 2001). As a result, in most organizations, they undergo systematic, iterative enhancements. BI systems need users' active involvement beyond the initial development process to provide valuable input, such as changing data dimensions, evolving business rules, resolving metadata conflicts, and so on, that the developers may otherwise overlook (Yeoh \& Koronios, 2010). After the initial deployment, users can provide input through functional testing to ensure the system meets its needs but, as the BI system gets used, users can be instrumental in suggesting and reviewing enhancements on an ongoing basis.

The user participation construct in the BI systems context needs to reflect this ongoing user involvement. Hence, our major departure from existing studies, which largely concentrate on user participation in the early phases of the development process, is an enhanced connotation of this concept-that of users' involvement throughout a system's lifecycle (i.e., not merely in a system's initial development but, more importantly, in its ongoing evolution), an aspect that has not been studied (Pagano \& Bruegge, 2013). We define user participation as an organizational variable that denotes users' active involvement in the initial development phase and the post-deployment phases that affects the continued development and evolution of systems.

We define user participation based on the structurational model of technology in which Orlikowski (1992) portrays "human interaction with technology as having two iterative modes: the design mode and the use mode" (p. 408). She argues that, rather than positing the two modes as "disconnected moments or stages in a technology's lifecycle, the structurational model of technology posits artifacts as potentially modifiable throughout their existence". She further observes that, "we also need to acknowledge the differences among technologies in the degree to which users can affect redesign" (Orlikowski, 1992, p. 408). In the context of $\mathrm{BI}$ technologies, this aspect of the structurational model (namely, user-affected change) is an important foundation for developing our constructs and hypotheses.

Some characteristics of this user-centered development approach are similar to those of agile development methods (e.g., dynamic systems development method, scrum, and extreme programming) where intensive stakeholder involvement is central (Abelein, Sharp, \& Paech, 2013). These methods entail development cycles that enable one to make verifications and corrections, adapt to possible emerging changes, build functionality in steps via an incremental approach, and work collaboratively in a way that encourages feedback and suggestions at every stage (Mohammadi, Nikkhahan, \& Sohrabi, 2009).

An important feature of $\mathrm{BI}$ systems such as those that provide managerial decision making support is their interactive nature. For actively involved users, the interactivity leads to their more quickly realizing benefits (a sense of immediate control over the decision making process) and more clearly understanding potential benefits (including what more they can expect from the system) (Hwang, Ku, Yen, \& Cheng, 2004). This interaction leads to more user demands and shorter feedback-improvement cycles. Thus, user participation in the $\mathrm{BI}$ systems context is more intense and enduring than that in traditional IS development. It includes users' participation in configuring, customizing, and improving the BI system and articulating the need for newer and more comprehensive data in an ongoing manner.

\subsubsection{The Mediating Role of User Participation}

In companies whose top management believes that BI plays a strategically important role in their business, the top management subtly yet consistently communicates this belief to managers in business units. This metastructuring action introduces powerful signification structures in which the users of $\mathrm{BI}$ systems begin to interact with the system's early versions. The signification structures allow users to develop a common understanding of the opportunities and risks associated with using new BI systems, which may involve reengineering business processes, instituting change management, and so on. A different type of metastructuring action is hiring analytically skilled talent, appointing $\mathrm{BI}$ champions at senior levels, and so on. This type of action creates new domination structures via an authoritative asymmetry in human capital, which helps reduce political resistance to change (Purvis et al., 2001). Another metastructuring action is 
defining guidelines for users' participation in the BI system usage by influencing work processes that include such systems (Yeoh \& Koronios, 2010). This action invokes a structure of domination that directs users to accomplish work systematically via standardized BI processes.

Overall, with these deliberate metastructuring actions, top management ensures a broader and deeper user participation in evolving BI systems on a consistent basis. The structurational model of technology explains how these metastructuring actions lead to technology structuring activities that impact the ongoing enhancement of $\mathrm{BI}$ capability through user participation. As the organization's managerial users continue to use the $\mathrm{BI}$ systems, they expect those systems to provide the right information content for their tasks. They also expect the right system functionality to support those tasks and adaptability to their workflow needs. We explain this phenomenon with examples of signification and domination structures in the following paragraphs.

Within a signification structure (that top management invokes through communicating the strategic importance of $\mathrm{BI}$ ), users reaffirm Bl's importance or challenge the discrepancy between its importance as top management evangelizes it and the reality on the ground. Both these behaviors indicate users' participation in continually evolving the $\mathrm{BI}$ systems and have the potential to enhance both information capability and $\mathrm{BI}$ system capability. For example, for certain strategically important decisions, one may need to drill down into more detailed information (e.g., growth in market share of a new product line in particular market segments) where such information is not available (although the system may be capable of accommodating such data if available). In addition, users may identify a need for exploring scenarios along additional dimensions, such as the supply chain, which may not be part of the current system build (although the relevant data may be available). Interactions with the system (structuring activities of users within the structure of signification) allow users to not only better understand the missed opportunity and the ensuing risk due to the lack of detailed information and/or capability of the $\mathrm{BI}$ system but also request/demand the missing detailed information and/or improvement in the system functionality ${ }^{2}$. Such recurring structuring activities shape the technology via user participation in the system's ongoing evolution.

A domination structure may direct users to follow a systematic guided workflow for making decisions using certain reports with projected information (e.g., production-scheduling decision given monthly sales projections). Guidelines may direct users to follow (and, thus, confirm) the workflow, but some may tweak the workflow based on their perception of the reliability of information in the report. Again, both these activities potentially lead to enhanced information and $\mathrm{BI}$ system capability. For example, users may notice inconsistencies between the information presented in a report and the users' expectation based on experience. Alternatively, the workflow may be hard-coded in the current BI system; that is, the system might not support any deviation in the workflow. These interactions (structuring activities within the domination structure) cause users to better understand the reliability of the information in the report and/or the restrictions in the workflow that the current guidelines dictate. Such structuring activities of "participating" users result in positively affecting the information capability by including information from more reliable sources and/or enhancing the BI system capability with a more flexible workflow.

In general, by participating in the iterative system usage/improvement process (structuring activities) within the institutional structures of signification, domination, and legitimation that top management's metastructuring actions trigger, users: (1) discover whether they have adequate information for their decision making tasks and 2) provide constructive feedback (reinforcement and/or suggestions regarding the level of detail, reliability, timeliness, comprehensiveness, etc.). As a result, user participation enhances the firm's information capability. Thus, we hypothesize that:

H1: User participation mediates the relationship between top management championship and information capability.

Further, similar metastructuring actions of top management and structuring activities of users within the institutional structures help users to: 1 ) discover if the features of the $\mathrm{BI}$ systems they routinely use are adequate for their decision making needs and 2) provide constructive feedback (reinforcement and/or suggestions regarding additional functionalities to support their unsupported and evolving decision making needs). As a result, user participation enhances the firm's BI system capability. Thus, we hypothesize that:

H2: User participation mediates the relationship between top management championship and $\mathrm{BI}$ system capability.

\footnotetext{
${ }^{2}$ Note that using technology is one type of structuring action and participation in the system evolution is the second type of structuring action, which depicts the "dualism" in the interaction between the structural features of an organization and the human agents according to the structurational model of technology.
} 


\subsubsection{Analytical Decision Making Orientation}

We define analytical decision making orientation as an organizational variable that denotes the extent to which a firm encourages decision makers to systematically use data and facts and analyze them for their decision making tasks (Davenport, Harris, \& Morison, 2010; Kaufmann, Wagner, \& Carter, 2016; Sjöberg, 2003). The analytical decision making concept originates from the rational choice theory (Becker, 1978), which claims that individuals make optimal choices between specific and clearly defined alternatives to maximize a utility function while making decisions. Although originally theorized at the individual or decision-task level, more recent research has conceptualized decision rationality as an organizational variable to denote "a set of activities whereby organizational actors collectively produce rational decisions" (Cabantous \& Gond, 2011).

The observation that researchers conceived the decision analysis discipline as an applied, prescriptive discipline (Howard, 1988; Keeney, See, \& von Winterfeldt, 2006) that promotes the analytical perspective in decision making among organizational actors (managers, consultants) supports this conceptualization. As firms adopt $\mathrm{BI}$ systems, data analysis and analytical modeling become embedded in their decision making processes, which researchers have referred to as "model-based rationality" (March, 2006, p. 202) that one must observe as an organizational phenomenon because multiple actors can routinely participate in business processes with built-in rationality. Organizational researchers have referred to technology artifacts that embed analytical models of decision making as "rationality carriers" (Cabantous \& Gond, 2011). These rationality carriers have the potential to bring an organization to a higher state of analytical decision making orientation.

Although technology can act as a rationality carrier, it is insufficient for developing organizational capabilities by itself (Ulrich \& Lake, 1991). Hence, organizational researchers have called for research on rationality persistence in organizations via its distribution between humans and technology artifacts (Latour, 2005). Fostering analytical decision making values in employees is one way to ensure rationality persistence (Sadler-Smith \& Shefy, 2004). Decision makers need to undergo a systematic shift in their values to accept and embrace analytical decision making as a belief system. Our analytical decision making orientation construct represents the encouragement that employees at all levels of the organization perceive to make decisions based on information and evidence and to support ideas, opinions, proposals, and so on with facts and figures wherever possible. Advanced organizations in this direction show widespread respect for measurement and evaluation. In the context of $\mathrm{BI}$, such organizations readily use and exploit technologies that infuse rationality in decision making; they routinely perform complex analyses on large data sets to solve difficult problems, and their routine business processes incorporate analytical processing.

\subsubsection{The Mediating Role of Analytical Decision Making Orientation}

The mechanism through which top management infuses analytical decision making orientation in an organization is subtler than the mechanism through which it influences user participation: it does so through promoting a rational perspective in decision making among all actors. The extent to which organizational actors embrace data and analysis in decision making is a function of their perception of the importance that top management affords to such things. Although top management uses the same metastructuring actions to infuse both analytical decision making orientation and user participation perspectives, the institutional structures they invoke under the two perspectives and the structuring activities of human actors within those structures differ.

Under the analytical decision making orientation perspective, domination structures do not involve "imposing" guidelines so much as they involve "empowering" the managerial decision makers to use analytical decision making processes to accomplish outcomes and "reassuring" them of organizational backing when they make decisions rationally (Orlikowski, 1992) ${ }^{3}$. Decision makers reaffirm the structure by using evidence-based decision making principles to the extent they are appropriate for the tasks at hand. Their continued structuring activities calibrate the balance along the rationality continuum in routine decision making situations, which results in their explicitly articulating the type of information and tools they need to improve the performance of business processes. Legitimation structures guide the extent to which individuals engage in analytical decision making by their accepting and, thus, upholding prevailing norms. Legitimation structures make it reasonable or appropriate for individuals to expect a certain level of

\footnotetext{
${ }^{3}$ In Orlikowski's (1992, p. 405) interpretation, domination structures induce power into human interaction by providing organizational capabilities for humans to accomplish outcomes. Power is understood as "transformative capacity", the power of human action to transform the social and material world. We use this sense to interpret domination structures.
} 
information and systems support in their decision making tasks. This phenomenon works hand-in-hand with signification structures in that, individuals understand the implications and the positive consequences of making critical decisions based on facts and evidence. Signification structures serve as cognitive guides for decision makers to reinforce that the effectiveness of their decisions depends on accurate, timely, and comprehensive information. Thus, decision makers' structuring activities demand these characteristics in the information they use, which ultimately impacts the firm's information capability. These structuring activities also result in a demand for more sophisticated BI systems that can, for example, allow one to dig into different data dimensions, relax assumptions and expand the problem space, explore multifaceted scenarios through what-if analyses, build complex predictive models, and so on. As they are exposed to the same metastructuring actions and institutional structures, IT personal are also willing to entertain these challenging demands, which pushes the organization towards higher levels of information and BI system capabilities.

In general, by participating in an analytical decision making process within the institutional structures that top management's metastructuring actions trigger, users: 1) understand the implications of the quality of information and the characteristics of the BI systems on the outcome of their decision making tasks and 2) communicate and obtain the appropriate level of decision support needed for their tasks. As a result, analytical decision making orientation enhances a firm's information capability and BI system capability. Thus, we hypothesize that:

H3: Analytical decision making orientation mediates the relationship between top management championship and information capability.

H4: Analytical decision making orientation mediates the relationship between top management championship and BI system capability.

\section{Research Methodology}

\subsection{Operationalization of Constructs}

We developed a survey instrument based on appropriate measurements from previous available instruments and modified some existing scales to make them more suitable for the BI context. In addition, we created items for our specific constructs where we did not find appropriate matches. All constructs in the proposed model are based on reflective multi-item scales. We obtained responses on a Likert-type scale that ranged from strongly disagree (1) to strongly agree (5). We consulted a focus group of seven executives to validate the instrument. This panel provided feedback that led to minor changes for clarification. A pilot study conducted on the first batch of 59 survey responses showed the high reliability of the measurement instrument: the Cronbach's alphas (Nunnally, 1978) ranged from between 0.826 and 0.958. Table 2 presents the list of indicators used in the measurement model.

Table 2. Constructs and Measures

\begin{tabular}{|c|c|l|}
\hline Construct & ID & \\
\hline \multirow{4}{*}{$\begin{array}{c}\text { Top } \\
\text { management } \\
\text { championship } \\
\text { (MgmtCh) }\end{array}$} & MC1 & Top management considers that BI plays a strategically important role \\
\cline { 2 - 3 } & MC2 & Top management sponsors BI initiatives \\
\cline { 2 - 3 } & MC3 & Top management demonstrates commitment to BI via policy/guidelines \\
\hline \multirow{4}{*}{$\begin{array}{c}\text { User } \\
\text { participation } \\
\text { (UsrPrt) }\end{array}$} & UP1 & Users are committed to the success of BI systems \\
\cline { 2 - 3 } & UP2 & Users participate in the evaluation of BI systems \\
\cline { 2 - 3 } & UP4 & Users contribute to the ongoing improvement of BI systems \\
\hline \multirow{2}{*}{$\begin{array}{c}\text { Analytical } \\
\text { decision } \\
\text { making } \\
\text { orientation } \\
\text { (ADMOrn) }\end{array}$} & AO1 & Decision makers are encouraged to make informed, fact-based decisions \\
\cline { 2 - 3 } & AO2 & Decision makers are encouraged to look for data/information to support work \\
\cline { 2 - 3 } & AO3 & Decision makers are encouraged to measure/evaluate evidence \\
\cline { 2 - 3 } & AO4 & Decision makers are encouraged to use quantitative/numeric analysis \\
\hline
\end{tabular}


Table 2. Constructs and Measures

\begin{tabular}{|c|c|l|}
\hline \multirow{4}{*}{$\begin{array}{c}\text { Information } \\
\text { capability } \\
\text { (InfCap) }\end{array}$} & IC1 & Information provided by BI systems is comprehensive \\
\cline { 2 - 3 } & IC2 & Information provided by BI systems has an appropriate level of detail \\
\cline { 2 - 3 } & IC3 & Information provided by BI systems is reliable \\
\cline { 2 - 3 } & IC4 & Information provided by BI systems is timely \\
\hline \multirow{4}{*}{$\begin{array}{c}\text { BI system } \\
\text { capability } \\
\text { (BISCap) }\end{array}$} & BC1 & BI systems support workflow \\
\cline { 2 - 3 } & BC2 & BI systems allow exploration of alternative scenarios \\
\cline { 2 - 3 } & BC3 & BI systems are customizable \\
\cline { 2 - 3 } & BC4 & BI systems have needed features/functionality \\
\hline
\end{tabular}

For our two capability constructs, information capability (InfCap) and BI system capability (BISCap), we reviewed the literature on IT capability and BI capability (Bhatt \& Grover, 2005; Işık et al., 2013; Kim et al., 2011; Mithas et al., 2011; Wang et al., 2012) for similar constructs. We conceptualized the items we used to measure InfCap from Mithas et al.'s (2011) information management capability construct, which come from the Baldrige criteria for performance excellence (see NIST, 2002). While Mithas et al. (2011) directly use the Baldrige data, we translated the criteria to scale items that reflect the characteristics of information important to our construct (i.e., comprehensiveness, appropriateness of the level of detail, reliability (accuracy and consistency), and timeliness).

The BISCap construct concerns the extent to which the BI systems allow users to leverage the available information to suit their decision making needs. These characteristics include support for workflow, the ability to explore alternative scenarios, customizability to suit the differing process needs, and the availability of features and functionalities. Since this conceptualization is relatively new, we developed the BISCap scale items using procedures that Hinkin (1998) outlines: we first generated an item pool and worded each item to accurately reflect its conceptual difference from InfCap by emphasizing the information systems and not the information itself. Subsequently, we had other researchers and practitioners scrutinize the items for InfCap and BISCap and reduced their number based on an independent ranking before we validated them with the focus group and pilot survey along with the other constructs.

The scale for top management championship (MgmtCh) comprised four items that measured the intensity of top management's championship of $\mathrm{BI}$ via a mixture of items that captured both attitudinal and behavioral aspects. We adapted two items about the strategic importance of $\mathrm{BI}$ and communication of policy, guidelines, and so on from similar items that Kulkarni, Ravindran, and Freeze (2007), Liang et al. (2007), and Chatterjee et al. (2002) used. We created the other two items that referred to human resources with analytical skills and sponsorship of BI initiatives specifically for the BI context and validated them along with the rest of the instrument.

We derived the four items we used to measure user participation (UsrPrt) from prior studies on the development of such items (Barki \& Hartwick, 1994; McKeen \& Guimaraes, 1997; McKeen et al., 1994). We selected items that applied to different systems across multiple organizations and modified them to measure the degree of user participation in the continuous evolution of BI systems beyond the initial development phase.

Our four-item analytical decision making orientation (ADMOrn) scale measured the extent to which the organizational decision making processes embedded the beliefs and values of rationality in decision making as perceived by the decision makers at all levels. Because this conceptualization is also relatively new, we developed the ADMOrn scale using similar procedures we used to develop the capability scales. We designed the scale items to reflect our conceptual definition by emphasizing "encouragement" and "respect" for the elements of analytical decision making. We also had other researchers and practitioners scrutinize these items before we validated them with the focus group and pilot survey.

We included three control variables that we believed could impact BI capability: the firm's industry, the firm's size measured based on its number of employees, and the country in which it mainly operates. None of the control variables had any bearing on our results; hence, we excluded them from our model.

\subsection{Data Collection}

We administered the final global survey to groups of professionals who attended two-day intensive corporate executive seminars on $\mathrm{BI}$ strategy that targeted business leaders who make strategic and tactical decisions for their companies. One of the authors conducted these seminars in six countries: the 
United States, Mexico, Peru, Ecuador, India, and Vietnam. The respondents were experienced managers who were either directly responsible for $\mathrm{BI}$ initiatives or part of advisory teams with knowledge of $\mathrm{BI}$ systems in their respective companies. Barring a few exceptions, all respondents belonged to different companies and, hence, represented separate organizations. Out of the 520 collected surveys, 486 were fully completed. Table 3 lists the respondents' firms' industry type and number of employees.

Table 3. Industry Type and Company Size

\begin{tabular}{|c|c|c|c|}
\hline \multicolumn{2}{|c|}{ Industry Type } & \multicolumn{2}{c|}{ Company Size } \\
\hline Industry & Share & Number of employees & Share \\
\hline Banking, insurance, finance & $24.7 \%$ & $1-99$ & $17.9 \%$ \\
\hline Service & $12.3 \%$ & $100-499$ & $22.6 \%$ \\
\hline Information technology & $11.4 \%$ & $500-999$ & $16.7 \%$ \\
\hline Manufacturing & $9.0 \%$ & 1000 or more & $42.8 \%$ \\
\hline Government & $6.9 \%$ & & \\
\hline Healthcare & $5.2 \%$ & & \\
\hline Energy & $4.9 \%$ & & \\
\hline Telecommunications & $3.7 \%$ & & \\
\hline Mining and related & $1.9 \%$ & & \\
\hline Travel and tourism & $1.7 \%$ & & \\
\hline Agriculture and food & $0.9 \%$ & & \\
\hline Other & $17.4 \%$ & & \\
\hline
\end{tabular}

\section{Data Analysis and Results}

\subsection{Measurement Model}

We first examine the reliability and validity measures for the model constructs. Table 4 presents the descriptive statistics of the indicators and the reliability and discriminant validity measures of the constructs. The results show that all the constructs had Cronbach's alphas well above the 0.70 cutoff point (Nunnally 1978) and composite factor reliability values that exceeded the recommended 0.70 threshold (Segars, 1997). The AVE values for the constructs also exceeded the 0.50 threshold (Segars, 1997), which indicates that the constructs captured a relatively high level of variance (Fornell \& Larcker, 1981). As such, we can conclude that the instrument had a high level of instrument reliability.

Table 4. Reliability and Validity Measures

\begin{tabular}{|c|c|c|c|c|c|c|c|}
\hline Construct & ID & Mean & $\begin{array}{l}\text { Standard } \\
\text { deviation }\end{array}$ & $\begin{array}{c}\text { Cronbach's } \\
\text { alpha }\end{array}$ & $\begin{array}{c}\text { Composite } \\
\text { reliability }\end{array}$ & $\begin{array}{l}\text { Average } \\
\text { variance } \\
\text { extracted }\end{array}$ & $\begin{array}{c}\text { Standardized } \\
\text { factor } \\
\text { loadings }\end{array}$ \\
\hline \multirow{4}{*}{$\begin{array}{c}\text { Top } \\
\text { management } \\
\text { championship } \\
\text { (MgmtCh) }\end{array}$} & MC1 & 3.67 & 1.095 & \multirow{4}{*}{0.9258} & \multirow{4}{*}{0.9477} & \multirow{4}{*}{0.8193} & 0.84 \\
\hline & MC2 & 3.46 & 1.144 & & & & 0.92 \\
\hline & MC3 & 3.42 & 1.079 & & & & 0.95 \\
\hline & MC4 & 3.36 & 1.146 & & & & 0.79 \\
\hline \multirow{4}{*}{$\begin{array}{l}\text { User } \\
\text { participation } \\
\text { (UsrPrt) }\end{array}$} & UP1 & 3.11 & 1.004 & \multirow{4}{*}{0.9046} & \multirow{4}{*}{0.9330} & \multirow{4}{*}{0.7769} & 0.77 \\
\hline & UP2 & 2.97 & 1.052 & & & & 0.86 \\
\hline & UP3 & 3.01 & 1.063 & & & & 0.91 \\
\hline & UP4 & 2.99 & 1.077 & & & & 0.82 \\
\hline \multirow{4}{*}{$\begin{array}{l}\text { Analytical } \\
\text { decision } \\
\text { making } \\
\text { orientation } \\
\text { (ADMOrn) }\end{array}$} & $\mathrm{AO} 1$ & 3.68 & 1.003 & \multirow{4}{*}{0.8681} & \multirow{4}{*}{0.9099} & \multirow{4}{*}{0.7163} & 0.84 \\
\hline & $\mathrm{AO} 2$ & 3.81 & 0.936 & & & & 0.92 \\
\hline & $\mathrm{AO} 3$ & 3.58 & 0.985 & & & & 0.95 \\
\hline & $\mathrm{AO} 4$ & 3.61 & 0.990 & & & & 0.79 \\
\hline
\end{tabular}


Table 4. Reliability and Validity Measures

\begin{tabular}{|c|c|c|c|c|c|c|c|}
\hline \multirow{4}{*}{$\begin{array}{l}\text { Information } \\
\text { capability } \\
\text { (InfCap) }\end{array}$} & IC1 & 3.33 & 1.002 & \multirow{4}{*}{0.8426} & \multirow{4}{*}{0.8944} & \multirow{4}{*}{0.6792} & 0.78 \\
\hline & IC2 & 3.23 & 1.000 & & & & 0.78 \\
\hline & IC3 & 3.50 & 0.982 & & & & 0.76 \\
\hline & IC4 & 3.46 & 1.067 & & & & 0.71 \\
\hline \multirow{4}{*}{$\begin{array}{l}\text { BI system } \\
\text { capability } \\
\text { (BISCap) }\end{array}$} & BC1 & 3.27 & 1.063 & \multirow{4}{*}{0.8764} & \multirow{4}{*}{0.9154} & \multirow{4}{*}{0.7305} & 0.71 \\
\hline & $\mathrm{BC} 2$ & 2.91 & 1.088 & & & & 0.80 \\
\hline & BC3 & 2.97 & 1.114 & & & & 0.84 \\
\hline & BC4 & 2.94 & 1.056 & & & & 0.87 \\
\hline
\end{tabular}

We performed a confirmatory factor analysis to establish the convergent and discriminant validity by estimating the measurement model using the Mplus software (version 7.3.1) developed by Muthén and Muthén (2003). Table 4 also presents the standardized factor loadings of the indicators on their latent factors. All factor loadings were well above the recommended threshold; hence, each item showed convergence to its proper latent factor. The t-values for the factor loadings indicated statistical significance (at $p$ values $=0.000$ ). The $R^{2}$ values for the indicators were also high (ranging from 0.50 to 0.89 ), which supports the assertion that the indicators were good measures of the construct (Bollen, 1989).

We assessed discriminant validity by testing whether each latent variable shared more variance with its own measurement items than with the other constructs (Fornell \& Larcker, 1981). Table 5 confirms that each construct's correlation values with other constructs were less than the square root of AVE for that construct, which provides more evidence of the discriminant validity of the constructs.

Table 5. Correlations between Latent Variables and Square Roots of Average Variance Extracted

\begin{tabular}{|c|c|c|c|c|c|}
\hline & MgmtCh & UsrPrt & ADMOrn & InfCap & BISCap \\
\hline MgmtCh & $\mathbf{0 . 9 0 5}$ & 0.488 & 0.690 & 0.406 & 0.446 \\
\hline UsrPrt & & $\mathbf{0 . 8 8 1}$ & 0.478 & 0.371 & 0.471 \\
\hline ADMOrn & & & $\mathbf{0 . 8 4 6}$ & 0.465 & 0.450 \\
\hline InfCap & & & & $\mathbf{0 . 8 2 4}$ & 0.590 \\
\hline BISCap & & & & & $\mathbf{0 . 8 5 5}$ \\
\hline
\end{tabular}

Furthermore, we estimated the model using the mean-adjusted maximum likelihood (MLM) estimator in Mplus, which adjusts the estimation result for any non-normality in data. We evaluated the model using multiple goodness of fit criteria. The $X^{2}$ statistics for the model $\left(X^{2}=366.16, d f=160, p=0.000\right)$ rejected the null hypothesis. However, since the model $X^{2}$ statistic is highly sensitive to sample size, the significance of the $x^{2}$ test is not a sufficient reason by itself to reject a model (Wang \& Wang, 2012, p. 45). Both the comparative fit index $(\mathrm{CFI}=0.962)$ and Tucker-Lewis index $(T L I=0.955)$ were greater than 0.90 , which indicates a good fit. The estimated value of the root mean square error of approximation (RMSEA = 0.051 ) was in the range of good fit $(0.05-0.08)$. The upper limit of its 90 percent $\mathrm{Cl}(0.045,0.058)$ was well below the boundary (i.e., $<0.08)$, and the fit test $(P=0.352$; i.e., probability RMSEA $<=0.05$ ) showed a close fit. Moreover, the standardized root mean square residual $(S R M R=0.044)$ was less than 0.08, which is another indication of a good fit. Hence, overall we conclude the model fit was good.

Finally, because we collected the data for all model variables with the same instrument, we examined the potential for common method bias in our data using two approaches that Podsakoff, MacKenzie, Lee, and Podsakoff (2003) prescribe. First, we used a common method construct approach that compares the estimated structural model path coefficients with and without the common method construct. We found no significant differences, which suggests common method bias was not an issue in our data. Second, we performed Harman's single-factor test, which revealed the presence of distinct factors in the unrotated factor solution. Although these results do not completely rule out the possibility of common method variance, they suggest that common method variance does not likely explain the reported effects (Andersson \& Bateman, 1997). 


\subsection{Structural Model: Multiple Mediator Analysis}

Having established the validity of the measurement model, we then evaluated the structural model using Mplus (Muthén \& Muthén, 2003). We analyzed the mediating roles of UsrPrt and ADMOrn on the two BI capability variables, InfCap and BISCap, respectively. Our structural model included two variables that simultaneously mediated the effect of MgmtCh on the two capability variables; as such, we needed to estimate the specific indirect effect of each mediator conditional on the presence of the other mediator. Including multiple putative mediators in one structural model also reduces the likelihood of parameter bias due to omitted variables. Given the presence of multiple mediators, collinearity between UsrPrt and ADMOrn plays a role (in much the same way as in ordinary multiple regression). One can reasonably expect the mediators to be correlated by virtue of their mutual reliance on the independent variable, MgmtCh, which is likely to attenuate the mediators' effects on the capability variables. In our structural model, we allowed the residual covariance between UsrPrt and ADMOrn to be freely estimated in order to obtain an accurate estimation of the specific indirect effects.

As Preacher and Hayes (2008) prescribe for multiple mediator models and Zhao, Lynch, and Chen (2010) elaborate on, we adopted the following procedure to test the hypotheses regarding each mediator on each dependent variable:

First (step 1), we investigated the specific indirect effect associated with each mediator, UsrPrt and ADMOrn. With this step, we could determine to what extent each mediator mediated the effect of MgmtCh on the capability variables conditional on the presence of the other mediator.

Second (step 2), we investigated the direct effect of MgmtCh on each capability variable in the presence of the two mediators. With this step, we could determine the type of mediation (complementary, competitive, or indirect-only mediation (Zhao et al., 2010) if detected in Step 1)).

Note that, in the case of multiple mediators, a significant total indirect effect is not a prerequisite for investigating specific indirect effects. It is entirely possible to find specific indirect effects to be significant in the absence of a significant total indirect effect. Also, note that a significant zero-order effect of the independent variable on the dependent variables, popularized by Baron and Kenny (1986) as an "effect to be mediated", is not a prerequisite for investigating specific indirect effects (Zhao et al., 2010).

Mplus (Muthén \& Muthén, 2003) is one of the few software packages with the capability to estimate specific indirect effects of multiple mediators ${ }^{4}$. Moreover, Mplus allows bootstrapping for estimating the standard errors of specific and total indirect effects in multiple mediator models along with the bootstrap confidence interval $(\mathrm{Cl})$ for each mediator for the 90, 95, and 99 percentiles. In addition, to account for the asymmetrical nature of the percentile bootstrap Cls, Mplus allows bias-corrected bootstrapped Cls, which simulation studies have reported to be superior (Briggs, 2006; Williams \& MacKinnon, 2008). We adapted the Mplus syntax that Preacher and Hayes (2008, p. 889) provide to our model variables for estimating the specific indirect effects using bias-corrected bootstrapping with 5,000 resamplings of our data.

Table 6 shows the results of our structural model. As the results of step 1 show, all of the estimates of specific indirect effects were positive and significant and well within their bias-corrected bootstrapped $95 \% \mathrm{Cls}$. Hence, we conclude that both UsrPrt $\left(\beta=0.07^{\star}\right)$ and ADMOrn $\left(\beta=0.178^{\star \star \star}\right)$ mediated the MgmtCh $\rightarrow$ InfCap path. These results support Hypotheses 1 and 2 . Similarly, both UsrPrt $\left(\beta=0.118^{\star \star \star}\right)$ and ADMOrn $\left(\beta=0.107^{\star *}\right)$ also mediated the MgmtCh $\rightarrow$ BISCap path. These results support Hypotheses 3 and 4 .

The results of step 2 show that the direct influence of MgmtCh on InfCap in the presence of the mediators was not significant ( $\beta=0.093 \mathrm{~ns}$ ). We followed the decision-tree algorithm that Zhao et al. (2010, p. 201) prescribe to further classify the type of each indirect effect identified in step 1 in the MgmtCh $\rightarrow$ InfCap path. Accordingly, the type of mediation that both UsrPrt and ADMOrn exhibited on the effect of MgmtCh on InfCap was "indirect-only" or full mediation. On the other hand, the step 2 results show the direct influence of MgmtCh on BISCap was positive and significant $\left(\beta=137^{\star}\right)$ in the presence of the mediators. Hence, the type of mediation that UsrPrt and ADMOrn exhibited on the effect of MgmtCh on BISCap was "complementary" or partial mediation. Both these results are consistent with the hypothesized theoretical framework. While the two mediators fully mediated the MgmtCH $\rightarrow \operatorname{InfCap}$ path, the MgmtCh $\rightarrow \mathrm{BISCap}$

\footnotetext{
${ }^{4}$ As far as we know, Mplus is one of the few software programs with this capability. Other software (e.g., AMOS's bootstrapping function for the mediation test) only reports the total indirect effect of all the mediators together. SPSS and SAS can estimate specific indirect effects with the help of specially written macros, but these macros can only use directly observed variables and not latent variables as in our case.
} 
path's partial mediation suggests that MgmtCh had some direct effect on BISCap and/or that this path contained an omitted mediating variable.

Table 6. Results of the Multiple Mediator Structural Model for Specific Indirect Effects

\begin{tabular}{|c|c|c|c|c|c|c|c|c|}
\hline & \multicolumn{3}{|c|}{ MgmtCh $\rightarrow$ InfCap path } & \multicolumn{3}{|c|}{ MgmtCh $\rightarrow$ BISCap path } \\
\hline & & & \multirow{2}{*}{$\begin{array}{c}\text { Point } \\
\text { estimate }\end{array}$} & \multicolumn{2}{|c|}{ Bias-corrected $95 \% \mathrm{Cl}$} & \multirow{2}{*}{$\begin{array}{c}\text { Point } \\
\text { estimate }\end{array}$} & \multicolumn{2}{|c|}{ Bias-corrected $95 \% \mathrm{Cl}$} \\
\hline & & & & Lower & Upper & & Lower & Upper \\
\hline \multirow{3}{*}{ Step 1} & Specific & UsrPrt & $0.070^{\star}$ & 0.017 & 0.131 & $0.118^{\star \star \star}$ & 0.068 & 0.177 \\
\hline & effect of: & ADMOrn & $0.178^{\star \star \star}$ & 0.086 & 0.290 & $0.107^{\star \star}$ & 0.026 & 0.194 \\
\hline & & & \multicolumn{3}{|c|}{ InfCap } & \multicolumn{3}{|c|}{ BISCap } \\
\hline Step 2 & $\begin{array}{c}\text { Direct } \\
\text { effect of: }\end{array}$ & MgmtCh & \multicolumn{3}{|c|}{$0.093 \mathrm{~ns}$} & \multicolumn{3}{|c|}{$0.137^{*}$} \\
\hline
\end{tabular}

\section{Discussion}

Our findings reveal important insights about the organizational phenomena associated with building $\mathrm{BI}$ capabilities. Prior research has primarily focused on the IT capability-firm performance link. As that research has matured and firms have recognized the importance of building IT-related capabilities, we now need to focus our research efforts in a different direction; that is, on how to build such capabilities. Our results open a new door for future researchers to look at the antecedents of technology-related capabilities. We theorized and found how top management championship for $\mathrm{BI}$ acts through two different constructs, user participation and analytical decision making orientation to develop BI capability, a special type of technology capability. We discuss the theoretical implications in the paragraphs below (see Figure 2 for summary). Subsequently, we discuss our study's implications for practice, the limitations of our work, and possible avenues for future research.

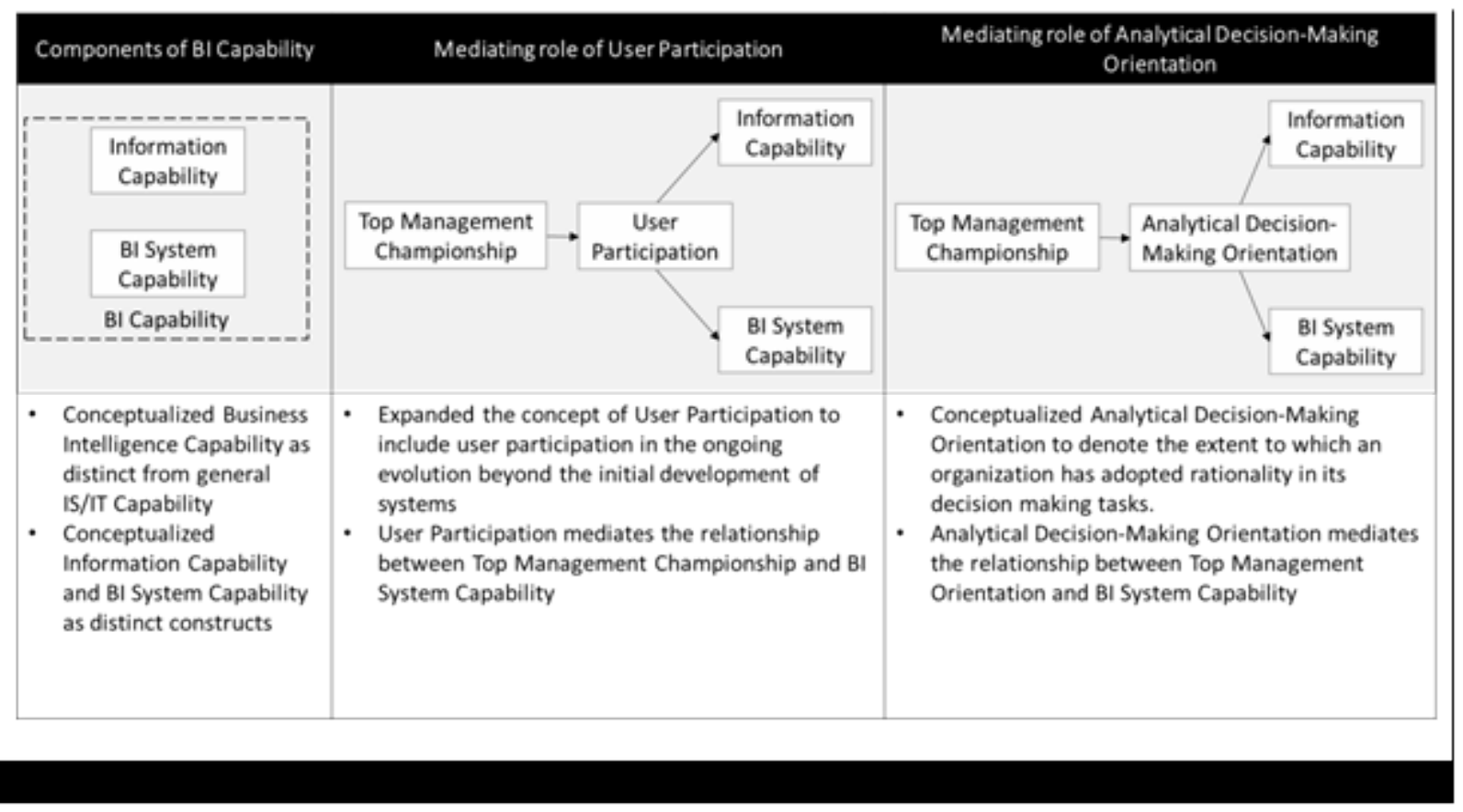

Figure 2. Theoretical Implications 


\subsection{Implications for Theory}

\subsubsection{Conceptualization of BI Capability}

We argue that $\mathrm{BI}$ capability differs from other general IT/IS-related capabilities and, drawing on the structurational model of technology, theorize the organizational conditions that stimulate its creation. We believe our work is an early attempt to distinguish the organizational capability attributed to a specific type of systems, Bl systems (as opposed to general information systems), which, mainly due to their managerial use in higher-level decision making, play a significant role in a firm's performance and competitive standing (Işık et al., 2013; Popovič et al., 2014). We conceptualize BI capability as having two distinct components: information capability and BI system capability (Figure 2, column 1). While our results indicate that organizations need similar conditions for building and enhancing the two capabilities, the theoretical conceptualization has important implications for studying the phenomenon in detail. Higher capability of one kind or another (information or systems) may have different impacts on business performance in various contexts. For example, researchers may theorize that variability in firm characteristics, such as customer focus versus internal focus, industry sector type (data-rich versus datapoor), predominant decision type (operational versus strategic), and time-sensitivity of important decisions (real-time versus deliberate), may account for the variability in information and/or BI system capability. Our conceptualization also makes it possible to study how the two types of $\mathrm{Bl}$ capabilities impact firm performance in such different contexts.

\subsubsection{Enhanced Conceptualization of User Participation}

Our research is among the first to conceptualize user participation in the context of contemporary information systems that do not necessarily follow the traditional design-code-test-implement process. We expand the meaning of this construct to denote users' involvement in the configure-customize-improve process that is characterized by evaluation and constructive feedback. Our study treats user participation as an attribute of an organization and provides a fresh conceptualization of this construct.

\subsubsection{Conceptualization of Analytical Decision Making Orientation}

Our research is also one of the first to explore analytical decision making as an organizational phenomenon that impacts $\mathrm{BI}$ capability. Prior research has studied the concept of rationality in decision making and advanced it from the individual to organizational level where technology innovations facilitate embedding rationality in organization-wide decision processes. We point out that the persistence of rationality in organizations is possible when it is carefully distributed between humans and technology. Recognizing that this balance involves changing values and belief systems across an organization, we introduced and operationalized a new construct (namely, analytical decision making orientation) as an attribute of an organization.

\subsubsection{Mediating Roles of User Participation and Analytical Decision Making Orientation}

Our findings contribute to a renewed understanding of the complex relationships between the role of top management and $\mathrm{BI}$ capability. With the enriched conceptualization of user participation and analytical decision making orientation, we identify the important mediating roles these variables play in influencing the development of $\mathrm{BI}$ capability. One may deem these observations one of the most important findings in the domain of $\mathrm{BI}$ capability research at the organizational level of analysis.

No prior research has posited the role of user participation in BI capability's development and the mechanism through which it takes effect. We hypothesized and found that an organization's management influences, through various metastructuring actions, how the organization builds $\mathrm{BI}$ capability by engaging the workforce (Figure 2, column 2). Previous research has mainly studied the relationship between top management support and IS success in the context of a particular information system in a single organization and/or has not included user participation in the mix of organizational variables. Alternatively, the research that has included user participation has studied its influence only during a system's initial development phase. We found that, in the context of BI systems, given the type of its user, the voluntary nature of its use, and the flexibility with which it is put to use, user participation plays an important mediating role. Our results show that an involved user base influences information capability and the $\mathrm{BI}$ system capability via structuring activities. This finding is likely to have a profound influence on the way researchers model user participation and test its relationships with dependent variables. For example, researchers can not only study if user participation, as defined here, leads to improved BI capabilities but also study its impact on the performance of affected business processes. 
We also found that an organization's top management that views $\mathrm{BI}$ as a strategic investment foments an analytically disposed environment that encourages informed decision making mainly based on evidence, which, in turn, is a precursor to building BI capability (Figure 2, column 3). Prior research has looked at the persistence of rationality in decision making as an organizational phenomenon (Cabantous \& Gond, 2011; Latour, 2005; March, 2006) but has not explicitly studied it in the context of management championship or BI capability. We found that top management's metastructuring actions, which encourage behavioral norms such as looking for data and information that support analytical decision making whenever possible, having a mindset that respects evaluating decisions by measuring outcomes, and incorporating analytics systematically into business processes, actually create the conditions for rational decision making to thrive, which, in turn, influences both information capability and $\mathrm{BI}$ system capability. This finding opens up opportunities for studying how top management can employ an organic approach to building a long-term, value-based shift towards instituting a fact-based decision making culture if it wants to increase an organization's BI capability.

Overall, our results show that top management championship influences BI capability. While the two mediating variables fully mediated top management championship's relationship with information capability, it only partially mediated its relationship with BI system capability. One may explain the former result with the general observation that top management does not usually directly attempt to improve information content and quality; it usually does so indirectly by encouraging users and elevating the importance of information resources across the organization. On the other hand, the partial mediation of the path to BI system capability indicates that top management does have some direct influence on how an organization builds $\mathrm{BI}$ system capability. The partial mediation finding also opens up research opportunities for theorizing and discovering an unknown omitted variable in this path.

\subsection{Implications for Practice}

Managers should be aware that $\mathrm{BI}$ capability has two distinct components and that they need separate attention. Moreover, managers must recognize that the ways and means to improve the two capabilities differ. An organization needs to possess a repository of accurate, dependable, and consistent information that is available at the appropriate level of detail across all its units. Myriad BI systems with the functionality to support the cognitive process of the various types of managerial decision makers can leverage this information.

Top management should recognize that it can influence how an organization builds BI capability. While it cannot directly build technically advanced information repositories and BI systems, our findings show it can influence the creation of such capability by paving the path for it in two ways: 1) by encouraging users to be engaged as meaningful contributors in advancing technology that supports their decision making tasks and 2) inspiring evidence-based decision making.

First, top management should create a climate in which the right kinds of users-that is, those who will take the necessary steps-succeed. Having decided that BI should play an important role in its business, top management can plant the seeds of a value system that encourages and respects analytical decision making throughout the organization. Explicitly, top management can do so by sponsoring BI projects, investing in analytical expertise at various levels, rewarding exemplars, and communicating with the actors at all company levels the importance of Bl's role. Through these explicit and visible actions, top management can create the right conditions for analytical decision making to flourish.

Second, top management can also create an "involved" user base-a managerial workforce that is not just a passive user of the $\mathrm{BI}$ systems but one that actively participates in continually improving the systems they routinely use via submitting feedback and suggestions, critically evaluating the functionalities, asking for enhancements, trying out new features, and, in general, being responsible for their success. Top management can create such a user base by directing business units to create work processes that include formal and informal user participation. Moreover, it can facilitate conformance by appointing champions in key leadership positions and restructuring strategic teams to include cross-functional representations.

\subsection{Limitations and Future Research}

To assess our study's contributions to theory and practice, we examine its limitations, which also open opportunities for future research. Our survey participants were senior executives that their companies sponsored to attend a relatively expensive multi-day BI-strategy seminar. It is possible that companies that choose to invest in their leadership in this manner have a higher predisposition to $\mathrm{BI}$ in general, which can indirectly lead to selection bias and skew the results. Future research should validate our findings with 
a more controlled sample. Our research model did not account for the maturity of $\mathrm{BI}$ practice in the companies. The managerial and technological learning associated with the experience with $\mathrm{BI}$ practices may affect the results. Future research may investigate the validity of our research model across early and late adopters of $\mathrm{BI}$ technologies.

Further, while we theorize user participation and analytical decision making orientation as mediators of top management championship in developing BI capability, certain organizational conditions (e.g., worker empowerment; team orientation, orientation toward creating change; and the firm's strategic direction, goals, objectives, and espoused culture) (Srite \& Karahanna, 2006) might still facilitate or hinder the mediating relationships and have a moderating influence on them. Future research could also explore the dynamics of the mediating effects over time. For example, researchers might employ a longitudinal research design to examine the process through which and why top management championship might have a greater impact in certain organizations. In addition, future researchers may delve deeper into the top management championship construct by carefully selecting the specific types of metastructuring actions of the top management-resource provisioning, change encouragement, participation in decision making (Dong et al., 2009) -in the BI context to theorize the pertinent influences of top management on the development of both aspects of BI capability.

\section{Conclusion}

Drawing on the structurational model of technology and motivated by the business value of the IT literature, we develop a theoretical model of organizational factors instrumental in building capabilities in the domain of $\mathrm{Bl}$. Our research model explains the roles of user participation and analytical decision making orientation as propagating mechanisms that transmit top management championship's positive effects to BI capability's development. Our hypotheses explicate the mediating roles of user participation and analytical decision making orientation.

Our results illustrate that top management championship indirectly affects the development of $\mathrm{BI}$ capability through multiple pathways. Prior studies may have oversimplified some of top management championship's seemingly direct impacts on IT capability, assimilation, and so on. Moreover, this study is one of the first attempts to closely examine the antecedents of BI capability and, thus, advances the extant literature, which has largely focused on IT-related capabilities' impact on firm performance. The results also provide instrumental insights for managers to foster user participation and fact-based decision making values when promoting the advancement of $\mathrm{BI}$ in organizations. We hope that this work inspires future attempts at a more elaborate and comprehensive understanding of such capability-building phenomena. 


\section{References}

Abelein, U., Sharp, H., \& Paech, B. (2013). Does involving users in software development really influence system success? IEEE Software, 30(6), 17-23.

Andersson, L. M., \& Bateman, T. S. (1997). Cynicism in the workplace: Some causes and effects. Journal of Organizational Behavior, 18(5), 449-469.

Aral, S., \& Weill, P. (2007). IT assets, organizational capabilities, and firm performance: How resource allocations and organizational differences explain performance variation. Organization Science, 18(5), 763-780.

Audzeyeva, A., \& Hudson, R. (2016). How to get the most from a business intelligence application during the post implementation phase? Deep structure transformation at a U.K. retail bank. European Journal of Information Systems, 25(1), 29-46.

Barki, H., \& Hartwick, J. (1994). Measuring user participation, user involvement, and user attitude. MIS Quarterly, 18(1), 59-82.

Baron, R. M., \& Kenny, D. A. (1986). The moderator-mediator variable distinction in social psychological research: Conceptual, strategic, and statistical considerations. Journal of Personality and Social Psychology, 51(6), 1173-1182.

Barua, A., Konana, P., Whinston, A. B., \& Yin, F. (2004). An empirical investigation of net-enabled business value. MIS Quarterly, 28(4), 585-620.

Becker, G. S. (1978). The economic approach to human behavior. Chicago, IL: University of Chicago Press.

Bharadwaj, A. S. (2000). A resource-based perspective on information technology capability and firm performance: An empirical investigation. MIS Quarterly, 24(1), 169-196.

Bhatt, G. D., \& Grover, V. (2005). Types of information technology capabilities and their role in competitive advantage: An empirical study. Journal of Management Information Systems, 22(2), 253-277.

Bollen, K. (1989). Structural equations with latent variables. New York, NY: Wiley and Sons.

Briggs, N. E. (2006). Estimation of the standard error and confidence interval of the indirect effect in multiple mediator models (unpublished doctoral dissertation). The Ohio State University.

Cabantous, L., \& Gond, J.-P. (2011). Rational decision making as performative Praxis: explaining rationality's éternel retour. Organization Science, 22(3), 573-586.

Chae, H.-C., Koh, C. E., \& Prybutok, V. R. (2014). Information technology capability and firm performance: contradictory findings and their possible causes. MIS Quarterly, 38(1), 305-326.

Chatterjee, D., Grewal, R., \& Sambamurthy, V. (2002). Shaping up for e-commerce: Institutional enablers of the organizational assimilation of Web technologies. MIS Quarterly, (2), 65-89.

Davenport, T. H., Harris, J. G., \& Morison, R. (2010). Analytics at work: Smarter decisions, better results. Boston, MA: Harvard Business School Publishing.

Davern, M. J., \& Kauffman, R. J. (2000). Discovering potential and realizing value from information technology investments. Journal of Management Information Systems, 16(4), 121-143.

Dewett, T., \& Jones, G. R. (2001). The role of information technology in the organization: a review, model, and assessment. Journal of Management, 27(3), 313-346.

Dong, L., Neufeld, D., \& Higgins, C. (2009). Top management support of enterprise systems implementations. Journal of Information Technology, 24(1), 55-80.

Elbashir, M. Z., Collier, P. A., \& Davern, M. J. (2008). Measuring the effects of business intelligence systems: The relationship between business process and organizational performance. International Journal of Accounting Information Systems, 9(3), 135-153.

Eppler, M. J. (2006). Managing information quality: Increasing the value of information in knowledgeintensive products and processes (2nd ed.). Berlin: Springer. 
Fornell, C., \& Larcker, D. F. (1981). Evaluating structural equation models with unobservable variables and measurement error. Journal of Marketing Research, 18(1), 39-50.

Gartner. (2016a). Gartner identifies the top 10 strategic technology trends for 2016. Retrieved from http://www.gartner.com/newsroom/id/3143521

Gartner. (2016b). Insights from the 2016 Gartner ClO agenda report. Retrieved from https://www.gartner.com/imagesrv/cio/pdf/cio_agenda_insights_2016.pdf

Giddens, A. (1979). Central problems in social theory: Action, structure, and contradiction in social analysis. Berkeley, CA: University of California Press.

Giddens, A. (1984). The constitution of society: Outline of the theory of structuration. Berkeley, CA: University of California Press.

Gold, A. H., Malhotra, A., \& Segars, A. H. (2001). Knowledge management: An organizational capabilities perspective. Journal of Management Information Systems, 18(1), 185-214.

Grublješič, T., \& Jaklič, J. (2015). Business intelligence acceptance: The prominence of organizational factors. Information Systems Management, 32(4), 299-315.

Guimaraes, T., \& Igbaria, M. (1997). Client/server system success: Exploring the human side. Decision Sciences, 28(4), 851-876.

Habjan, A., Andriopoulos, C., \& Gotsi, M. (2014). The role of GPS-enabled information in transforming operational decision making: an exploratory study. European Journal of Information Systems, 23(4), 481-502.

Hartwick, J., \& Barki, H. (1994). Explaining the role of user participation in information system use. Management Science, 40(4), 440-465.

He, J., \& King, W. R. (2008). The role of user participation in information systems development: Implications from a meta-analysis. Journal of Management Information Systems, 25(1), 301-331.

Hinkin, T. R. (1998). A brief tutorial on the development of measures for use in survey questionnaires. Organizational Research Methods, 1(1), 104-121.

Howard, R. A. (1988). Decision analysis: Practice and promise. Management Science, 34(6), 679-695.

Hwang, H.-G., Ku, C.-Y., Yen, D. C., \& Cheng, C.-C. (2004). Critical factors influencing the adoption of data warehouse technology: A study of the banking industry in Taiwan. Decision Support Systems, 37(1), 1-21.

Işık, Ö., Jones, M. C., \& Sidorova, A. (2013). Business intelligence success: The roles of BI capabilities and decision environments. Information \& Management, 50(1), 13-23.

Jarvenpaa, S. L., \& Ives, B. (1991). Executive involvement and participation in the management of information technology. MIS Quarterly, 15(2), 205-227.

Karimi, J., Somers, T. M., \& Bhattacherjee, A. (2007). The role of information systems resources in ERP capability building and business process outcomes. Journal of Management Information Systems, 24(2), 221-260.

Kaufmann, L., Wagner, C. M., \& Carter, C. R. (2016). Individual modes and patterns of rational and intuitive decision-making by purchasing managers. Journal of Purchasing and Supply Management.

Keeney, R. L., See, K. E., \& von Winterfeldt, D. (2006). Evaluating academic programs: With applications to u.s. graduate decision science programs. Operations Research, 54(5), 813-828.

Keil, M. (1995). Pulling the plug: Software project management and the problem of project escalation. MIS Quarterly, 19(4), 421-447.

Kim, G., Shin, B., Kim, K. K., \& Lee, H. G. (2011). IT capabilities, process-oriented dynamic capabilities, and firm financial performance. Journal of the Association for Information Systems, 12(7), 487-517.

Kulkarni, U. R., Ravindran, S., \& Freeze, R. (2007). A knowledge management success model: Theoretical development and empirical validation. Journal of Management Information Systems, 23(3), 309-347. 
Latour, B. (2005). Re-assembling the social: An introduction to actor-network theory. Oxford, UK: Oxford University Press.

Lewis, W., Agarwal, R., \& Sambamurthy, V. (2003). Sources of influence on beliefs about information technology use: An empirical study of knowledge workers. MIS Quarterly, 27(4), 657-678.

Li, X., Hsieh, J. J. P.-A., \& Rai, A. (2013). Motivational differences across post-acceptance information system usage behaviors: An investigation in the business intelligence systems context. Information Systems Research, 24(3), 659-682.

Liang, H., Saraf, N., Hu, Q., \& Xue, Y. (2007). Assimilation of enterprise systems: The effect of institutional pressures and the mediating role of top management. MIS Quarterly, 31(1), 59-87.

Lu, Y., \& Ramamurthy, K. (2011). Understanding the link between information technology capability and organizational agility: An empirical examination. MIS Quarterly, 35(4), 931-954.

Luftman, J., \& Ben-Zvi, T. (2010). Key issues for IT executives 2009: Difficult economy's impact on IT. MIS Quarterly Executive, 9(1), 49-59.

March, J. G. (2006). Rationality, foolishness, and adaptive intelligence. Strategic Management Journal, 27(3), 201-214.

Markus, L. M., \& Mao, J.-Y. (2004). Participation in development and implementation-updating an old, tired concept for today's IS contexts. Journal of the Association for Information Systems, 5(11), 514544.

McKeen, J. D., \& Guimaraes, T. (1997). Successful strategies for user participation in systems development. Journal of Management Information Systems, 14(2), 133-150.

McKeen, J. D., Guimaraes, T., \& Wetherbe, J. C. (1994). The relationship between user participation and user satisfaction: An investigation of four contingency factors. MIS Quarterly, 18(4), 427-451.

Melville, N., Kraemer, K., \& Gurbaxani, V. (2004). Information technology and organizational performance: An integrative model of IT business value. MIS Quarterly, 28(2), 283-322.

Mishra, S., Modi, S. B., \& Animesh, A. (2013). The relationship between information technology capability, inventory efficiency, and shareholder wealth: A firm-level empirical analysis. Journal of Operations Management, 31(6), 298-312.

Mithas, S., Ramasubbu, N., \& Sambamurthy, V. (2011). How information management capability influences firm performance. MIS Quarterly, 35(1), 237-256.

Mohammadi, S., Nikkhahan, B., \& Sohrabi, S. (2009). Challenges of user Involvement in extreme programming projects. International Journal of Software Engineering and Its Applications, 3(1), 1932.

Muthén, B. O., \& Muthén, L. (2003). The comprehensive modeling program for applied researchers user guide. Los Angeles, CA: Muthén \& Muthén.

NIST. (2002). Criteria for performance excellence. Retrieved from http://baldrige.nist.gov/

Nunnally, J. C. (1978). Psychometric theory (2nd ed.). New York, NY: McGraw-Hill.

Orlikowski, W. J. (1992). The duality of technology: Rethinking the concept of technology in organizations. Organization Science, 3(3), 398-427.

Orlikowski, W. J., Yates, J., Okamura, K., \& Fujimoto, M. (1995). Shaping electronic communication: The metastructuring of technology in the context of use. Organization Science, 6(4), 423-444.

Pagano, D., \& Bruegge, B. (2013). User involvement in software evolution practice: A case study. In Proceedings of the 35th International Conference on Software Engineering.

Pavlou, P. A., \& El Sawy, O. A. (2006). From IT leveraging competence to competitive advantage in turbulent environments: The case of new product development. Information Systems Research, 17(3), 198-227.

Piccoli, G., \& Ives, B. (2005). Review: IT-dependent strategic initiatives and sustained competitive advantage: a review and synthesis of the literature. MIS Quarterly, 29(4), 747-776. 
Podsakoff, P. M., MacKenzie, S. B., Lee, J. Y., \& Podsakoff, N. P. (2003). Common method biases in behavioral research: A critical review of the literature and recommended remedies. Journal of Applied Psychology, 88(5), 879-903.

Popovič, A., Hackney, R., Coelho, P. S., \& Jaklič, J. (2012). Towards business intelligence systems success: Effects of maturity and culture on analytical decision making. Decision Support Systems, 54(1), 729-739.

Popovič, A., Hackney, R., Coelho, P. S., \& Jaklič, J. (2014). How information-sharing values influence the use of information systems: An investigation in the business intelligence systems context. The Journal of Strategic Information Systems, 23(4), 270-283.

Preacher, K. J., \& Hayes, A. F. (2008). Asymptotic and resampling strategies for assessing and comparing indirect effects in multiple mediator models. Behavior Research Methods, 40(3), 879891.

Purvis, R. L., Sambamurthy, V., \& Zmud, R. W. (2001). The assimilation of knowledge platforms in organizations: An empirical investigation. Organization Science, 12(2), 117-135.

Raghunathan, S. (1999). Impact of information quality and decision-maker quality on decision quality: a theoretical model and simulation analysis. Decision Support Systems, 26(4), 275-286.

Ragu-Nathan, B. S., Apigian, C. H., Ragu-Nathan, T. S., \& Tu, Q. (2004). A path analytic study of the effect of top management support for information systems performance. Omega, 32(6), 459-471.

Ravichandran, T., Lertwongsatien, C., \& Lertwongsatien, C. (2005). Effect of information systems resources and capabilities on firm performance: A resource-based perspective. Journal of Management Information Systems, 21(4), 237-276.

Sabherwal, R., \& Jeyaraj, A. (2015). Information technology impacts on firm performance: An extension of Kohli and Devaraj (2003). MIS Quarterly, 39(4), 809-836.

Sabherwal, R., Jeyaraj, A., \& Chowa, C. (2006). Information System Success: Individual and Organizational Determinants. Management Science, 52(12), 1849-1864.

Sadler-Smith, E., \& Shefy, E. (2004). The intuitive executive: Understanding and applying "gut feel" in decision-making. Academy of Management Executive, 18(4), 76-91.

Sanders, N. R., \& Premus, R. (2005). Modeling the relationship between firm IT capability, collaboration, and performance. Journal of Business Logistics, 26(1), 1-23.

Santhanam, R., \& Hartono, E. (2003). Issues in linking information technology capability to firm performance. MIS Quarterly, 27(1), 125-153.

Segars, A. H. (1997). Assessing the unidimensionality of measurement: A paradigm and illustration within the context of information systems research. Omega, 25(1), 107-121.

Sharma, R., \& Yetton, P. (2003). The Contingent Effects of Management Support and Task Interdependence on Successful Information Systems Implementation. MIS Quarterly, 27(4), 533556.

Sjöberg, L. (2003). Intuitive vs. analytical decision making: which is preferred? Scandinavian Journal of Management, 19(1), 17-29.

Srite, M., \& Karahanna, E. (2006). The role of espoused national cultural values in technology acceptance. MIS Quarterly, 30(3), 679-704.

Susarla, A., Barua, A., \& Whinston, A. B. (2010). Multitask Agency, Modular Architecture, and Task Disaggregation in SaaS. Journal of Management Information Systems, 26(4), 87-118.

Thong, J. Y. L., Yap, C.-S., \& Raman, K. S. (1996). Top Management Support, External Expertise and Information Systems Implementation in Small Businesses. Information Systems Research, 7(2), 248-267.

Ulrich, D., \& Lake, D. (1991). Organizational capability: Creating competitive advantage. The Executive, 5(1), 77-92. 
Wang, J., \& Wang, X. (2012). Confirmatory factor analysis structural equation modeling. New York: John Wiley \& Sons.

Wang, N., Liang, H., Zhong, W., Xue, Y., \& Xiao, J. (2012). Resource structuring or capability building? An empirical study of the business value of information technology. Journal of Management Information Systems, 29(2), 325-367.

Watson, H. J., Goodhue, D. L., \& Wixom, B. H. (2002). The benefits of data warehousing: Why some organizations realize exceptional payoffs. Information \& Management, 39, 491-502.

Williams, J., \& MacKinnon, D. P. (2008). Resampling and distribution of the product methods for testing indirect effects in complex models. Structural Equation Modeling, 15(1), 23-51.

Wixom, B. H., \& Quaadgras, A. (2013). GUESS?, Inc.: Engaging the business community with the "new look" of business intelligence. MIT Sloan CISR, XIII(8).

Wixom, B. H., \& Todd, P. A. (2005). A theoretical integration of user satisfaction and technology acceptance. Information Systems Research, 16(1), 85-102.

Wixom, B. H., \& Watson, H. J. (2001). An empirical investigation of the factors affecting data warehousing success. MIS Quarterly, 25(1), 17-41.

Yeoh, W., \& Koronios, A. (2010). Critical success factors for business intelligence systems. Journal of Computer Information Systems, 50(3), 23-32.

Zhao, X., Lynch, J. G., \& Chen, Q. (2010). Reconsidering Baron and Kenny: Myths and truths about mediation analysis. Journal of Consumer Research, 37(2), 197-206.

Zhu, K. (2004). The complementarity of information technology infrastructure and e- commerce capability: A resource-based assessment of their business value. Journal of Management Information Systems, 21(1), 167-202.

Zhu, K., \& Kraemer, K. L. (2002). E-commerce metrics for net-enhanced organizations: Assessing the value of e-commerce to firm performance in the manufacturing sector. Information Systems Research, 13(3), 275-29. 


\section{About the Authors}

Uday Kulkarni is an Associate Professor of Information Systems at Arizona State University's W.P. Carey School of Business. He earned his PhD in MIS from the University of Wisconsin, Milwaukee. He has over 35 years of teaching and industry experience in database management, business analytics, and knowledge management. His current research focuses on building organizational capabilities in business analytics and knowledge management. He has published his research in journals such as Journal of Management Information Systems, Decision Sciences, Decision Support Systems, IEEE Transactions on Knowledge and Data Engineering, and IEEE Transactions on Software Engineering. He was the founding director of the University's two masters programs: Information Management and Business Analytics. He conducts presentations and executive seminars on business analytics strategy for senior level audiences all over the world. He has been recognized for excellence in teaching on numerous occasions. He is a board member and a former chair of SIGDSA, an international special interest group in decision support and analytics.

José Antonio is an Associate Professor of Information Systems at ESAN Graduate School of Business, Universidad ESAN, in Lima, Perú. He is currently the Academic Associate Director of the Business Intelligence Executive Program at ESAN. He earned a PhD from Arizona State University - W.P. Carey School of Business where he went with a Fulbright scholarship, an MBA from ESAN and a B.S. in Computer Science from Francisco Marroquin University (Guatemala). He is a visiting professor, at Universidad de Chile, ESPOL in Ecuador, UNITEC in Honduras and Universidad Francisco Marroquín in Guatemala. His research interests include Business Intelligence, Knowledge Management and the value of IS. He has published in journals such as Decision Support Systems, Journal of World Business, Communications of the ACM, Communications of the AIS, International Journal of Business Intelligence Research, International Journal on Internet and Enterprise Management, and Revista Latinoamericana $y$ del Caribe de la Asociación de Sistemas de Información.

Aleš Popovič is an Associate Professor of Information Management at Faculty of Economics - University of Ljubljana and a visiting professor at NOVA IMS - Universidade Nova de Lisboa. His research interests include understanding IS value, success, and related business process change, both within and between organizations. He has published his research in a variety of academic journals, such as the Journal of the Association for Information Systems, the Journal of Strategic Information Systems, Decision Support Systems, Expert Systems with Applications, Journal of the Association for Information Science and Technology, Information Systems Frontiers, Government Information Quarterly, and Journal of Business Research, among others. He is on the Editorial Board of International Journal of Information Management, Industrial Management \& Data Systems, and International Journal of Business Intelligence Research.

Copyright $(02017$ by the Association for Information Systems. Permission to make digital or hard copies of all or part of this work for personal or classroom use is granted without fee provided that copies are not made or distributed for profit or commercial advantage and that copies bear this notice and full citation on the first page. Copyright for components of this work owned by others than the Association for Information Systems must be honored. Abstracting with credit is permitted. To copy otherwise, to republish, to post on servers, or to redistribute to lists requires prior specific permission and/or fee. Request permission to publish from: AIS Administrative Office, P.O. Box 2712 Atlanta, GA, 30301-2712 Attn: Reprints or via email from publications@aisnet.org. 